\title{
Shorepower Truck Electrification Project (STEP) - 2013
}

The Fleet Test and Evaluation Team at the U.S. Department of Energy's National Renewable Energy Laboratory (NREL) is evaluating and documenting the use of shorepower at 50 planned American Recovery and Reinvestment Act (ARRA)-funded truck stop electrification (TSE) sites across the nation. Trucks participating in the study have idle-reduction equipment installed that was purchased with rebates through the ARRA. A total of 5,000 rebates will be approved.

\section{Plug-In Infrastructure}

$\begin{array}{lrlc}\text { Reporting period } & 01 / 01 / 2013 \text { to } 12 / 31 / 2013 & \text { Number of TSE sites completed } & 50 \\ \text { Input Power } & 208 / 240 / 480 \mathrm{~V}(\min 50 \mathrm{~A}) 4 \text { wire circuit } & \text { Number of pedestals installed } & 313 \\ \text { Output Power } & 120 / 208 / 240 / 480 \mathrm{~V}, 20 / 30 \text { A outlets } & \text { Total vehicle capacity } & 1,252\end{array}$

Utilization Summary

\begin{tabular}{|c|c|c|c|c|c|}
\hline Idle-reduction rebate approvals & 4,370 & \multirow{3}{*}{$\begin{array}{l}\text { kWh } \\
5,000\end{array}$} & \multirow{2}{*}{ - Total kWh Used } & \multirow{2}{*}{ - Total Plug-In Events } & \multirow[b]{2}{*}{ Events } \\
\hline Completed equipment installations & 4,353 & & & & \\
\hline Number of TSE sites with $>90 \%$ uptime & 50 & & & & 350 \\
\hline Number of plug-in events & 2,703 & 4,000 & & & 300 \\
\hline Total hours booked & 40,740 & 3,000 & & & $\begin{array}{l}250 \\
200\end{array}$ \\
\hline Total kWh used & 28,089 & 2,000 & & & 150 \\
\hline Average kWh/event & 10.4 & 1.000 & & & 100 \\
\hline Gallons of diesel fuel saved ${ }^{1}$ & 32,592 & & & & 50 \\
\hline Metric tons of $\mathrm{CO}_{2}$ avoided ${ }^{2}$ & 332 & & 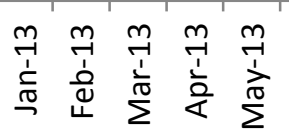 & 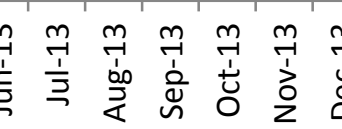 & \\
\hline
\end{tabular}

This chart shows the locations of all installed TSE sites. The size of each site indicator is relative to the amount of total kWh utilized there. Visit http://www.afdc.energy.gov/afdc/locator/tse/ for additional site information.

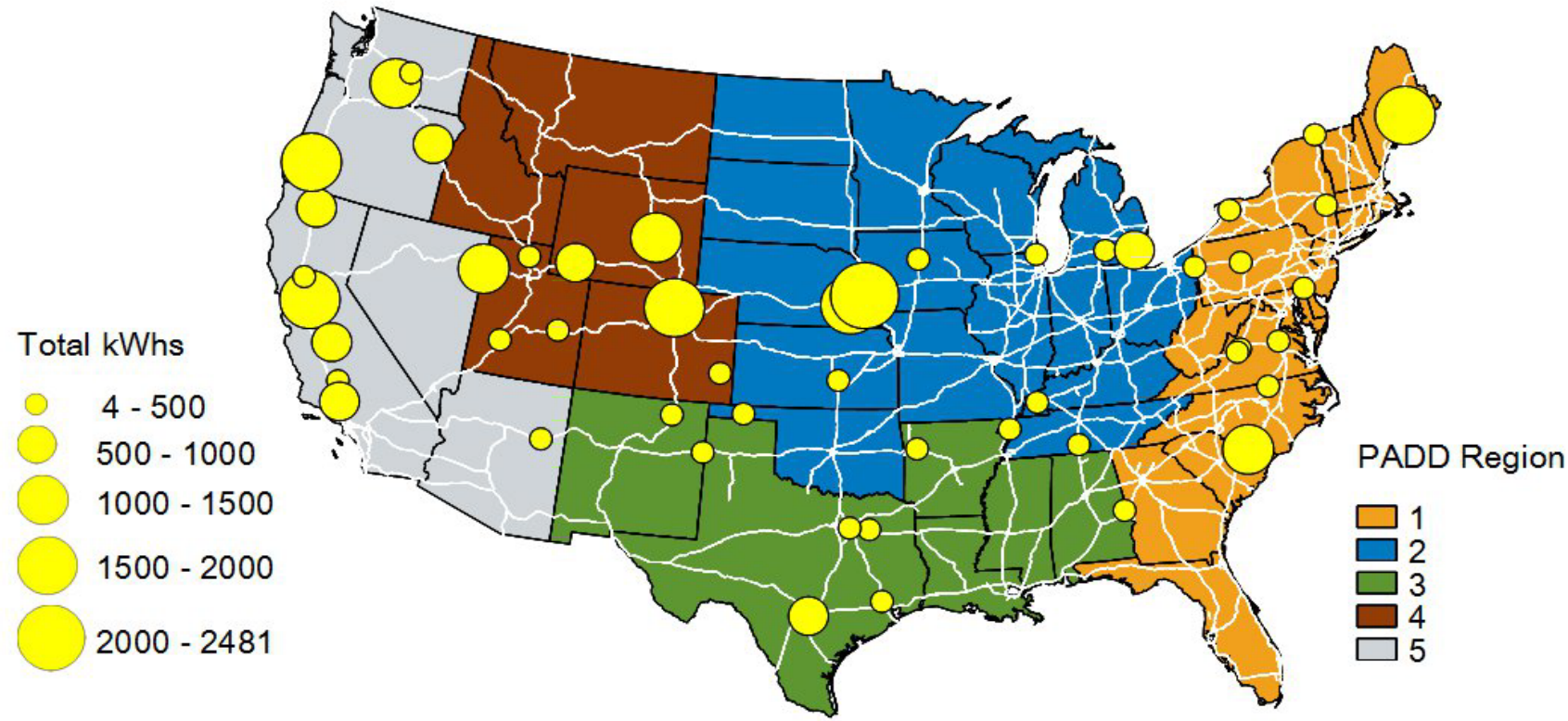

1. Gallons of diesel save calculated from booking time assuming 0.8 gallon / hour (EPA-420-F09-038).

2. Metric tons of carbon dioxide calculated using U.S. EPA greenhouse gas guidelines of $10,180 \mathrm{~g} \mathrm{CO}_{2} /$ gallon of diesel. 
Monthly Utilization Data

\begin{tabular}{lrrrr} 
& 2013-Q1 & 2013-Q2 & 2013-Q3 & 2013-Q4 \\
\cline { 2 - 5 } Number of plug-in events & 712 & 507 & 787 & 697 \\
\hline Number of plug-in events using STEP IDs & 46 & 39 & 62 & 34 \\
Total hours booked & 14,251 & 6,560 & 10,452 & 9,477 \\
\hline Total kWh used & 9,504 & 3,790 & 6,731 & 8065 \\
Average energy used per event (kWh) & 13.3 & 7.5 & 8.6 & 11.6 \\
Average power per event (kW) & 0.667 & 0.578 & 0.644 & 0.851 \\
Utilization Data & & & &
\end{tabular}

\section{Utilization Data}

\section{Geographic Utilization}

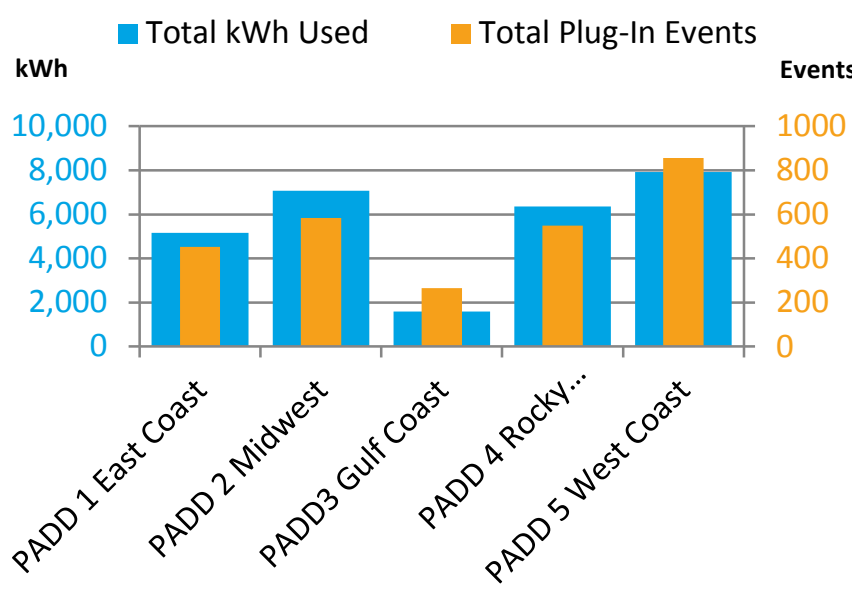

Booking Time Utilization

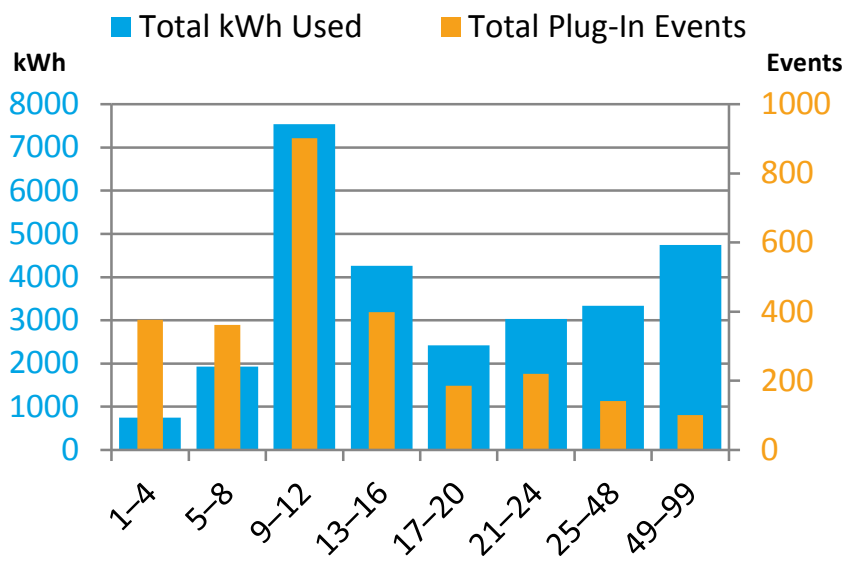

Hours Booked Per Event

\section{U.S. DEPARTMENT OF ENERGY}

Energy Efficiency \& Renewable Energy
Day of Week Utilization

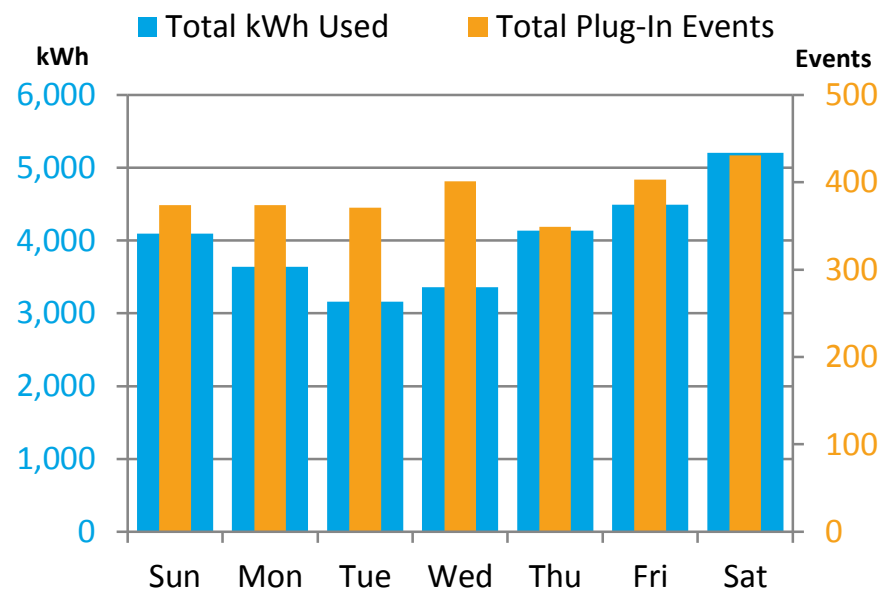

kWh Utilization

Total kWh Used Total Plug-In Events Events

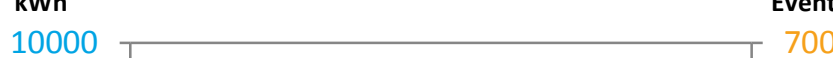

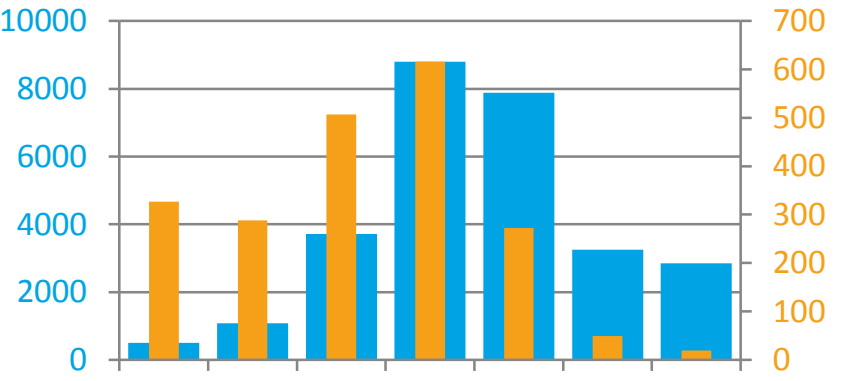

kWh Used Per Event

For more information, visit: vehicles.energy.gov

DOE/GO-102014-4382 • January 2014

Printed with a renewable-source ink on paper containing at least $50 \%$ wastepaper, including $10 \%$ post consumer waste.
Prepared by the National Renewable Energy Laboratory (NREL), a national laboratory of the U.S.

Department of Energy, Office of Energy Efficiency and

Renewable Energy; NREL is operated by the Alliance for Sustainable Energy, LLC. 